\title{
ENSEÑANZA ACTIVA Y RESPONSABILIDAD SOCIAL LOS ALUMNOS COMO PROTAGONISTAS ACTIVOS EN LA PREVENCIÓN DEL DENGUE.
}

Cristina Armúa ${ }^{1}$, Sandra Obregón ${ }^{2}$, Helena Soto Oca ${ }^{3}, \mathrm{Ma}$. Victoria Cubilla ${ }^{4}$, Laila Miguel ${ }^{5}$, Yolanda Peris ${ }^{6}$ y María de los Ángeles Botto $\left.{ }^{7 *}\right)$.

Palabras clave: Dengue - Aedes aegypti - promoción de la salud- - interacción niveles educativos- Didáctica de la Biología y Práctica de residencia.

\section{Resumen:}

Con el objetivo de concientizar a los diferentes actores sociales de la importancia del conocimiento del agente vector responsable de la enfermedad conocida como dengue, de realizar un trabajo integrado con docentes, residentes universitarios y alumnos del nivel medio de la provincia de Corrientes, para promover acciones de prevención de esta enfermedad; se abordó la problemática del Dengue en las aulas de diferentes instituciones educativas de nivel medio, por ser una problemática social que implicaba un compromiso institucional.. Dicho abordaje se realizó a través de diferentes actividades didácticas y se promovió la participación activa de actores de diferentes niveles educativos (docentes y alumnos de la universidad, del secundario, primario e inicial).

$\mathrm{El}$ interés de trabajar con los actores institucionales deviene del hecho de que la escuela constituye un importante centro de promoción y cuidado de la salud, ya que en ella se estimula el aprendizaje de conceptos, procedimientos y actitudes que intervienen activamente en la prevención de enfermedades.

Por otra parte, es oportuno mencionar que todo este trabajo se desarrolló en el marco de un Proyecto de Extensión financiado por la Secretaria General de Extensión (UNNE).

\section{Introducción:}

El dengue es definido como una enfermedad infectocontagiosa grave, ocasionada por un virus de ARN; para su transmisión necesita de un mosquito (llamado vector), el Aedes aegypti. Desde la aparición de ca-

\footnotetext{
${ }^{1}$ Cristina Armua: Profesor Titular. España 639. TE 03794-426285 -cel3794-349290- acarmua@exa.unne.edu.ar

${ }^{2}$ Sandra Obregón: Prof. Adjunta

${ }^{3}$ Helena Soto Oca: JTP

${ }^{4}$ María Victoria Cubilla: Auxiliar de primera

${ }^{5}$ Laila Miguel: Alumna de Didáctica de la Biología

${ }^{6}$ Yolanda Peris: docente de nivel medio

${ }^{7}$ María de los Ángeles Botto: docente de nivel medio

(*) Facultad de Ciencias Exactas y Naturales y Agrimensura (UNNE)- Av. Libertad 5470- 3400- Corrientes (Arg)
} 
sos autóctonos en nuestra ciudad, esta enfermedad se ha convertido en un problema más de salud pública.

El Aedes aegypti es un mosquito culícido que puede ser portador del virus del Dengue. Deposita sus huevos en cualquier lugar donde haya un poco de agua, allí ocurre la oviposición (puesta de huevos) y las sucesivas fases de desarrollo hasta la emergencia del adulto. Es decir, concientizar a la comunidad para que adopte medidas que eviten la formación de depósitos de agua, es una buena manera de hacer prevención para evitar este mal. Por otra parte, el ámbito donde mejor se puede actuar en este sentido es la institución escolar, ya que es reconocida la función formadora de la escuela.

La escuela constituye uno de los centros básicos de agrupación social, por lo que debemos considerarla como un medio privilegiado para la promoción exitosa de la educación sanitaria, cuando se busca que ésta incida en forma efectiva y masiva sobre la salud. Podemos decir entonces, que los docentes a través de una intervención activa en la enseñanza del Dengue contribuyen a mejorar la calidad de vida de las personas, a través de pautas que promueven en los alumnos la adquisición y puesta en práctica de actitudes responsables.

En esta oportunidad, y en el marco de un proyecto de extensión universitaria, docentes y alumnos de diferentes niveles educativos fueron promotores de salud al realizar una intervención educativa sobre Dengue en diferentes Instituciones escolares de la Ciudad de Corrientes, destacando que cada individuo debe tomar conciencia del rol que ocupa en el cuidado de su salud y la de su entorno como ser social.

\section{Metodología:}

Se trabajó con los alumnos de la asignatura Didáctica de la Biología y Práctica de Residencia de la carrera del Profesorado en Biología que realizaban sus prácticas de residencia, y con los alumnos de las instituciones educativas de nivel medio donde los primeros hacían sus prácticas. Entre dichas instituciones se pueden citar: Instituto Superior de Música "Carmelo H. De Biassi”, Colegio Secundario "Manuel Belgrano" ,Colegio Secundario "General San Martín”, Instituto Privado "San José", Colegio "Pío XI “ entre otros.

Los residentes llevaron a cabo clases teórico-prácticas en diferentes cursos del nivel secundario. Las actividades se centraron en las características morfológicas del Aedes aegypti, su ciclo biológico, fisiología y ecología; como así también en las medidas de prevención del Dengue. Se realizaron charlas de difusión a cargo de las responsables del proyecto, clases de laboratorio, con material biológico específicos para el reconocimiento y diferenciación del vector de la enfermedad, guía de actividades para la consolidación de información, entre otros materiales utilizados para la difusión y prevención.

Los alumnos de nivel secundario que fueron partícipes de dichas clases, confeccionaron diferentes materiales didácticos y de divulgación:

- láminas y folletos sobre la enfermedad y su vector (con imágenes y frases haciendo alusión a las medidas preventivas).

- almanaques informativo-preventivos

- rompecabezas

-juegos de la memoria

-títeres 
Finalmente, el material elaborado por los alumnos del secundario fue donado a distintas instituciones públicas de nuestra ciudad capital y del interior de la misma (de nivel primario e inicial); además de ser utilizado en una jornada de interacción entre los alumnos de los diferentes niveles educativos (alumnos de la UNNE y alumnos de nivel primario e inicial).

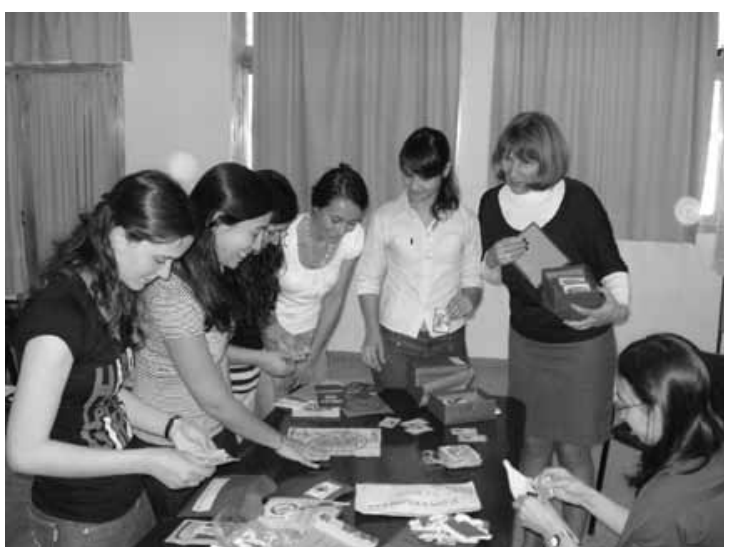

\section{Resultados}

El tema "Dengue" se trabajó en todos los colegios donde los residentes realizaron sus prácticas profesionales. Se apreció una adecuada transposición de contenidos, que favorecieron la apropiación del conocimiento por parte de los alumnos de nivel medio; resultando estas clases informativas y formativas sobre el Dengue y su prevención.

Se logró la elaboración de material didáctico y de difusión de una alta calidad, la interacción y generación de vínculos entre instituciones y actores de diferentes niveles educativos, la estimulación de buenos hábitos de salud en niños en edad escolar y preescolar.

Se distribuyó el material también a otros establecimientos educativos, de capital e in-

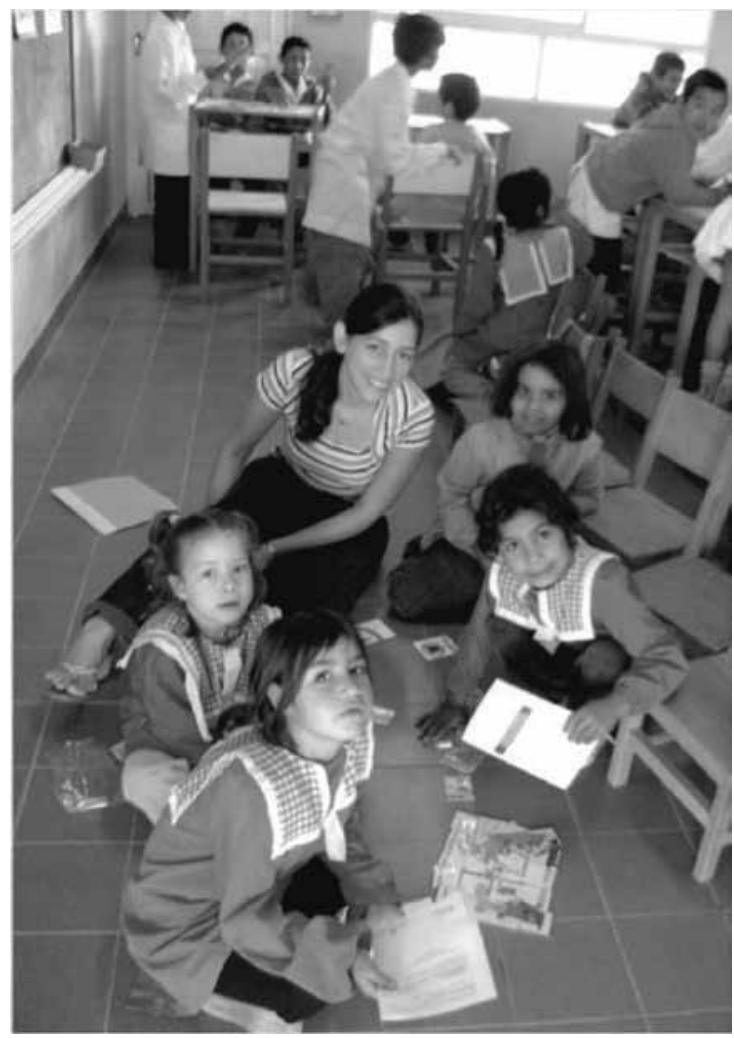

terior, lo que permitió colaborar con la prevención de este flagelo social, cumpliendo no solo los objetivos del proyecto sino tan bien del ministerio de salud de la provincia.

Finalmente podemos afirmar que se cumplieron los objetivos de promoción de la salud y de realización de un trabajo integrado entre docentes y alumnos de diferentes niveles educativos.

\section{Conclusiones:}

Podemos concluir que la implementación de este proyecto de extensión permitió que los propios educandos actúen como verdaderos agentes multiplicadores para concientizar a su entorno social sobre las implicancias de la enfermedad del Dengue y su prevención.

Dicha experiencia ha resultado muy enriquecedora ya que de la misma se obtuvie- 
ron valiosos resultados, que se reflejaron en: la calidad de las clases de los residentes universitarios y de las producciones de los alumnos del secundario, la repercusión del material y la jornada realizada en las instituciones de nivel primario e inicial. Cabe mencionar también que los alumnos destinatarios de esta actividad de extensión manifestaron motivación por concretar la presentación de los materiales solicitados y sensibilización en la toma de conciencia en pro del bien común.

\section{Bibliografía.}

- Armúa de Reyes, C. 2002. “Una Propuesta integrada en la enseñanza de la Biología”.Memorias de las V Jornadas Nacionales de Enseñanza de la Biología. La Educación en Biología:Tendencias e Innovaciones. Posadas (Misiones) Argentina. EditUniversitas. Córdoba. ISSN No 987. Pag 402-405.

- Martinez Torres E. 1998. Dengue y Dengue Hemorrágico. Jacc Impresores SA. Buenos Aires.

- PerezGomez A. Las funciones sociales de la escuela: de la reproducción a la reconstrucción crítica del conocimiento y la experiencia. P 17-18. En J. Gimeno Sacristán y A PerezGomez. Comprender y transformar la enseñanza. 11 ed. Morat ed. Madrid, 2005). 